\title{
Adverse Selection Revisited in the Context of Food Safety
}

\author{
Yukichika Kawata ${ }^{1}$ \\ ${ }^{1}$ Department of Animal and Food Hygiene, Obihiro University of Agriculture and Veterinary Medicine, Japan \\ Correspondence: Yukichika Kawata, Department of Animal and Food Hygiene, Obihiro University of \\ Agriculture and Veterinary Medicine, Inada-cho, Obihiro, Hokkaido 080-8555, Japan. Tel: 81-155-49-5424. \\ E-mail: ykawata@obihiro.ac.jp
}

Received: August 30, 2013

Accepted: September 12, 2013

Online Published: October 28, 2013

doi:10.5539/ibr.v6n11p160

URL: http://dx.doi.org/10.5539/ibr.v6n11p160

\begin{abstract}
Adverse selection is expected to occur with agricultural products because they are credence goods with respect to food safety. However, these products' safety levels are usually higher than the safety standards set by public agencies. This study suggests reasons for this phenomenon through theoretical examinations and numerical simulations, producing several results. First, even if we suppose that the cost functions of firms producing higher-quality products are in the upper regions, not only can firms producing the lowest-quality products remain in a 'market for lemons' but other firms can as well. Second, if we relax the above assumption about cost functions, even firms producing the highest-quality products can remain in a lemon market, while firms producing middle-quality products can increase their sales. Moreover, the WTP at some stage can be more than the initial WTP.
\end{abstract}

Keywords: adverse selection, credence goods, food safety, market for lemons

\section{Introduction}

A fundamental function of food is providing nutrition. Humans once needed to ensure a minimum calorie intake under income constraints. Rising income levels made it easier to acquire the necessary calories (Pritchett \& Summers, 1996). Later, humans purchased additional values such as taste and other qualities (Drewnowski, 1997; Blaylock, Smallwood, Kassel, Variyam \& Aldrich, 1999). For example, individuals spent their extra money on higher-quality foods (e.g., by shifting from pork to beef). Currently, after satisfying taste and other qualities, emphasis is being placed on food safety.

Economists usually categorise foods into search goods, experience goods, and credence goods (Nelson, 1970; Darby \& Karni, 1973). Many foods are affected by problems such as asymmetric information (e.g., when sellers have more information about goods than consumers) and imperfect information (e.g., when consumers cannot inspect the safety of vegetables) (Traill \& Koenig, 2010). This can produce a 'market for lemons' or an adverse selection (Akerlof, 1970).

Standard economics literature describes a market for lemons as one from which high-quality goods are eliminated because they are less profitable, leaving only low-quality goods. Akerlof explains the adverse selection mechanism by citing the used-car market as an example: used cars cannot be evaluated until after their new owners have driven them for a few days, and information on their sellers is limited because they are regular citizens who infrequently sell a small number of used cars. Used cars are thus categorised as 'experience goods'. Buying another used car (after experiencing mechanical problems, for example) is difficult because even used cars are relatively expensive. Thus, the trade between seller and consumer usually happens only once, and identifying the sellers of low-quality used cars is difficult.

The situation is somewhat different in food markets, such as that for agricultural products (e.g., vegetables and fruits). Degrees of food safety variability are often difficult for consumers to detect because the relevant factors are classified as 'credence quality' attributes (Henson \& Traill, 1993; Latvala \& Kola, 2002). However, public agencies can test for residual pesticides and uncover regulation violations. Food safety levels might vary among producers, but information on average (or prevailing) food safety levels and on substandard products is easy to find on the Internet and other media. We can therefore assume consumers are increasingly aware of the average food safety levels. It follows that they will purchase products when their willingness to pay (WTP) is, at most, as high as their willingness to pay for average quality products. Therefore, firms producing high-quality products 
should exit the market, and food safety levels should fall to the level defined by the safety standards set by public agencies. Product prices should also continue to fall.

Previous studies of this topic have introduced various systems for preventing adverse selection and securing food safety levels. Such systems have included a public certification system (Crespi \& Marette, 2001; Jahn, Schramm \& Spiller, 2005; Albersmeier, Schulze, Jahn \& Spiller, 2009), HACCAP (Starbird, 2005), safety standards systems (Hammoudi, Hoffmann \& Surry, 2009), and traceability systems (Sykuta, 2005; Starbird \& Amanor-Boadu, 2006; Starbird \& Amanor-Boadu, 2007). In addition, researchers have examined the most appropriate methods with which to implement these systems (for example, Farina, Gutman, Lavarello, Nunes \& Reardon, 2005; Cho \& Hooker, 2007).

However, food safety levels rarely fall to the level of existing safety standards, especially in developed countries where most firms satisfy the food safety standards set by public agencies to varying degrees. Further, despite the additional costs required to improve food safety (driven by the need for additional equipment and/or testing) and as reduced pesticide use increases the risk of disease and insect damage, products that offer higher safety levels are still being marketed, and at a price that does not fall. One possible explanation of this fact is an implicit assumption that firms in a market for lemons are homogeneous. Moreover, the possible reasons why adverse selection is not occurring in the agricultural products market include differences in cost structure, an inadequately examined issue. This paper is intended to fill this knowledge gap.

This paper examines the following two cases. First, while assuming that the cost functions of firms producing higher-quality products are high, we examine whether all firms but those producing the lowest-quality products will exit from a market for lemons. Second, we examine whether firms producing higher-quality products can increase their sales if we relax our assumption about cost functions.

The remainder of this paper is structured as follows. Sections 2 and 3 examine these questions theoretically in the context of a normal market and a market for lemons. Section 4 describes the numerical simulations for the selected cases. Finally, section 5 concludes the paper.

\section{Normal Market}

\subsection{Cost Functions}

Suppose there are three competitive markets in which a single agricultural product with varying quality levels is sold. Product quality level is divided into high, middle, and low (H, M, and L, respectively). Quality differences are observable in the market during purchase through the products' labels; thus, products $\mathrm{H}, \mathrm{M}$, and $\mathrm{L}$ appear similar, but are easily distinguishable by their labels. Countless homogeneous firms operate in each competitive market. Of these, we shall refer to one of these firms in market $\mathrm{H}, \mathrm{M}$ and $\mathrm{L}$ as 'firm H', 'firm M', and 'firm L', respectively.

Suppose a difference in quality means a difference in food safety, when other attributes are identical. As firm L in market $\mathrm{L}$ does not pay special attention to food safety, its total costs can be described as follows:

$$
T C\left(x_{L}\right)=V\left(x_{L}\right)+F
$$

where $V\left(x_{L}\right)$ and $F$ are the variable and fixed costs, respectively, and $x_{L}$ denotes the amount of product L. The marginal cost is then specified as the following equation:

$$
M C\left(x_{L}\right)=v\left(x_{L}\right)
$$

where $v\left(x_{L}\right)=\frac{d V\left(x_{L}\right)}{d x_{L}}$

Firms $\mathrm{M}$ and $\mathrm{L}$ in markets $\mathrm{M}$ and $\mathrm{L}$ pay more attention to the safety of their products. Therefore, let us suppose the marginal costs of firms $\mathrm{H}$ and $\mathrm{M}$ can be specified as follows:

$$
\begin{aligned}
& M C\left(x_{H}\right)=v\left(x_{H}\right)+\alpha_{H} \\
& M C\left(x_{M}\right)=v\left(v_{M}\right)+\alpha_{M}
\end{aligned}
$$

where $x_{H}$ and $x_{M}$ denote the amount of products $\mathrm{H}$ and $\mathrm{L}$, respectively and $v\left(x_{i}\right)=d V\left(x_{i}\right) / d x_{i}, i=H$, $M$.

\section{Assumption 1}

Let us suppose $\alpha_{H} \geq \alpha_{M} \geq 0$ and $v\left(x_{H}\right) \geq v\left(x_{M}\right) \geq v\left(x_{L}\right)$. 


\subsection{Demand Functions and Market Equilibrium}

The demand functions for products $\mathrm{H}, \mathrm{M}$, and $\mathrm{L}$ can be specified as follows:

$$
\begin{gathered}
p_{H}=W T P_{H}=W T P_{L}+\alpha_{H} \\
p_{M}=W T P_{M}=W T P_{L}+\alpha_{M} \\
p_{L}=W T P_{L}
\end{gathered}
$$

where $\alpha_{i}$ s are interpreted as the price premium when it is possible to distinguish product quality. Market equilibrium will be attained when $M C\left(x_{i}\right)=p_{i}, i=H, M, L$. Therefore, we have the following conditions:

$$
v\left(x_{i}\right)=W T P_{L}, i=H, M, L .
$$

For the sake of simplicity, we suppose $v\left(x_{i}\right)=k_{i} x_{i}(i=H, M, L)$ and $k_{i}>0(i=H, M, L)$ are constants. We then have the following condition:

$$
x_{i}=\frac{v\left(x_{i}\right)}{k_{i}}=\frac{W T P_{L}}{k_{i}}
$$

Let us denote the sales by firms $\mathrm{H}, \mathrm{M}$, and $\mathrm{L}$ as $x_{H}^{0}>0, x_{M}^{0}>0$, and $x_{L}^{0}>0$, respectively. If $k_{H}=k_{M}=$ $k_{L}$, then $x_{H}^{0} \leq x_{M}^{0} \leq x_{L}^{0}$ because cost function $M C\left(x_{M}\right)$ locates equal to or higher than $M C\left(x_{L}\right)$ and the same relationship holds between $M C\left(x_{H}\right)$ and $M C\left(x_{M}\right)$.

\section{Market for Lemons}

\subsection{First Stage}

Some of the assumptions above are modified in a market for lemons. Section 2 mentioned the labelling system that allows consumers to determine product quality and established that there are three competitive markets. In this section, however, we suppose that there is no such labelling system and that products $\mathrm{H}, \mathrm{M}$, and $\mathrm{L}$ are sold in the same competitive market (i.e. the market for lemons). Although countless firms operate in this market, we simplify by concentrating on three firms selling products that look similar, but have different food safety levels.

Here again, a difference in quality means a difference in food safety. For the sake of simplicity, let us suppose that the number of sales for firms $\mathrm{H}, \mathrm{M}$, and $\mathrm{L}$ at the beginning of the first stage are $x_{H}^{0}, x_{M}^{0}$, and $x_{L}^{0}$, respectively and that products $\mathrm{H}, \mathrm{M}$, and $\mathrm{L}$ are distributed uniformly in the market. It follows that the market shares of these firms are $x_{H}^{0} / x^{0}: x_{M}^{0} / x^{0}: x_{L}^{0} / x^{0}$, where $x^{0}=x_{H}^{0}+x_{M}^{0}+x_{L}^{0}$. We also suppose that consumers know these two facts (market shares and distribution). A consumer's willingness to pay for products in this market for lemons in the first stage can then be calculated as follows:

$$
\begin{gathered}
W T P_{\text {lemon }}^{0}=\left[W T P_{L}+\alpha_{H}\right] \frac{x_{H}^{0}}{x^{0}}+\left[W T P_{L}+\alpha_{M}\right] \frac{x_{M}^{0}}{x^{0}}+W T P_{L} \frac{x_{L}^{0}}{x^{0}} \\
=W T P_{L}+\frac{1}{x^{0}}\left[\alpha_{H} x_{H}^{0}+\alpha_{M} x_{M}^{0}\right]
\end{gathered}
$$

Note that $x_{i}^{0}=W T P_{L} / k_{i}(i=H, M, L)$ holds based on eq. (9).

\subsection{Firm $M$ in the First Stage}

In a market for lemons, firm M sells $x_{M}=x_{M}^{1}$ in the first stage, which can be calculated as follows. Because $M C\left(x_{M}\right)=W T P_{\text {lemon }}^{0}$, we have the following equation:

$$
x_{M}^{1}=\frac{1}{k_{M}}\left\{W T P_{L}+\frac{1}{x^{0}}\left[x_{H}^{0}\left(\alpha_{H}-\alpha_{M}\right)-x_{L}^{0} \alpha_{M}\right]\right\}
$$

If $x_{H}^{0}\left(\alpha_{H}-\alpha_{M}\right)-x_{L}^{0} \alpha_{M}=0$, from eqs. (9) and (11), $x_{M}^{1}=W T P_{L} / k_{M}=x_{M}^{0}$. Here, equation $x_{H}^{0}\left(\alpha_{H}-\alpha_{M}\right)$ $-x_{L}^{0} \alpha_{M}=0$ implies that firm M's total fixed cost for improving food safety is the same as the sum of the total fixed costs of firms $\mathrm{H}$ and $\mathrm{L}$ for their food safety improvement. For ease of notation, we denote $G_{M}^{0}=x_{H}^{0} \alpha_{H}+x_{L}^{0} / x_{H}^{0}+x_{L}^{0}$ and obtain the following result: 


$$
\text { If }\left\{\begin{array}{l}
\alpha_{M}>G_{M}^{0} \\
\alpha_{M}=G_{M}^{0} \\
\alpha_{M}<G_{M}^{0}
\end{array}\right\}, \quad \text { then }\left\{\begin{array}{c}
x_{M}^{1}<x_{M}^{0} \\
x_{M}^{1}=x_{M}^{0} \\
x_{M}^{1}>x_{M}^{0}
\end{array}\right\}
$$

\subsection{Firm H in the First Stage}

Firm H sells $x_{H}=x_{H}^{1}$, which can be calculated as follows. Because $M C\left(x_{H}\right)=W T P_{\text {lemon }}^{0}$, we have the following equation:

$$
x_{H}^{1}=\frac{1}{k_{H}}\left\{W T P_{L}+\frac{1}{x^{0}}\left[x_{M}^{0}\left(\alpha_{M}-\alpha_{H}\right)-x_{L}^{0} \alpha_{H}\right]\right\}
$$

Because $x_{M}^{0}\left(\alpha_{M}-\alpha_{H}\right)-x_{L}^{0} \alpha_{H}$ is negative, it follows that $x_{H}^{1}<x_{H}^{0}$.

\subsection{Firm L in the First Stage}

Firm L sells $x_{L}=x_{L}^{1}$, which can be calculated as follows. Because $M C\left(x_{L}\right)=W T P_{\text {lemon }}^{0}$, we have the following equation:

$$
x_{L}^{1}=\frac{1}{k_{L}}\left\{W T P_{L}+\frac{1}{x^{0}}\left[\alpha_{H} x_{H}^{0}+\alpha_{M} x_{M}^{0}+x_{L}^{0}\right]\right\}
$$

Because $\alpha_{H} x_{H}^{0}+\alpha_{M} x_{M}^{0}+x_{L}^{0}$ is positive, it follows that $x_{L}^{0}<x_{L}^{1}$.

\subsection{Second and Subsequent Stages}

In the second stage, the sales of firms $\mathrm{H}, \mathrm{M}$, and $\mathrm{L}$ are $x_{H}^{1}, x_{M}^{1}$, and $x_{L}^{1}$, respectively, and products $\mathrm{H}, \mathrm{M}$, and $\mathrm{L}$ are distributed uniformly in the market. It follows that the market shares of these firms are $x_{H}^{1} / x^{1}: x_{M}^{1} / x^{1}$ : $x_{L}^{1} / x^{1}$, where $x^{1}=x_{H}^{1}+x_{M}^{1}+x_{L}^{1}$. Therefore, a consumer's willingness to pay for a product is modified as follows:

$$
\begin{aligned}
W T P_{\text {lemon }}^{1} & =\left[W T P_{L}+\alpha_{H}\right] \frac{x_{H}^{1}}{x^{1}}+\left[W T P_{L}+\alpha_{M}\right] \frac{x_{M}^{1}}{x^{1}}+W T P_{L} \frac{x_{L}^{1}}{x^{1}} \\
& =W T P_{L}+\frac{1}{x^{1}}\left[\alpha_{H} x_{H}^{1}+\alpha_{M} x_{M}^{1}\right]
\end{aligned}
$$

Using the same procedures presented in subsections 3.2 to 3.4, we can easily show $x_{H}^{2} \leq x_{H}^{0}$ and $x_{L}^{2} \geq x_{L}^{0}$. The magnitude of the relationship between $x_{M}^{0}$ and $x_{M}^{2}$ is not conclusive. Therefore, the preposition below holds.

\section{Proposition 1}

In any stage $t$, the following relationships hold under assumption 1:

\section{Corollary 1}

$$
x_{H}^{0} \geq x_{H}^{t+1} \text {, and } x_{L}^{0} \leq x_{L}^{t+1} .
$$

Under assumption 1, the WTP at any stage $t$ is less than the initial WTP.

\section{Numerical Simulations}

\subsection{Incomplete Market for Lemons}

Although removing assumption 1 produces interesting findings, qualitative results are difficult to derive. Therefore, in this section, we conduct numerical simulations to examine three cases, some of which have assumption 1 removed. We use MS Excel for these numerical simulations. As mentioned in detail below, we set the parameter values and initial values of the sales by firms $\mathrm{H}, \mathrm{M}$, and $\mathrm{L}$ and calculate the dynamics of sales for 20 stages.

First, we examine the case where all three firms have the same cost functions except $\alpha_{i}$ as follows:

$$
M C\left(x_{i}\right)=k x_{i}+\alpha_{i}, i=H, M, L .
$$

We set $k=2, \alpha_{H}=4, \alpha_{M}=2, p_{H}=9, p_{M}=7$, and $p_{L}=5$. Among the distinct competitive markets, 
the sales for firms $\mathrm{H}, \mathrm{M}$, and $\mathrm{L}$ are 2, 2, and 2, respectively. Therefore, we use these values as the initial sales values for each firm in the market for lemons.

In this case, product $\mathrm{H}$ diminishes to zero at $t=2$, while product $\mathrm{M}$ and $\mathrm{L}$ remain in the market in the long run (see Figure 1). The sales of product $\mathrm{M}$ decrease, whereas those of product $\mathrm{L}$ increase. The numerical simulation suggests that, not only the firm producing the lowest-quality product, but also the other firms producing higher-quality products would remain in the market, even if the cost functions are the same but for term $\alpha_{i}$.

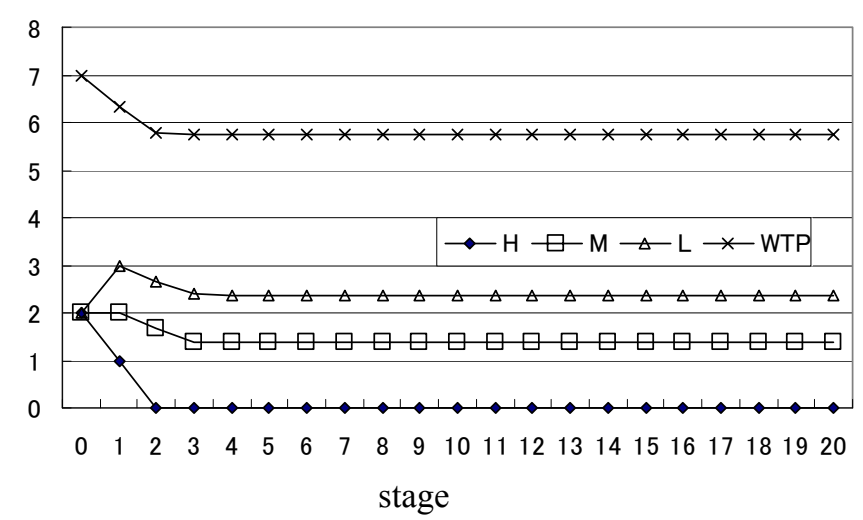

Figure 1. Example of an incomplete market for lemons

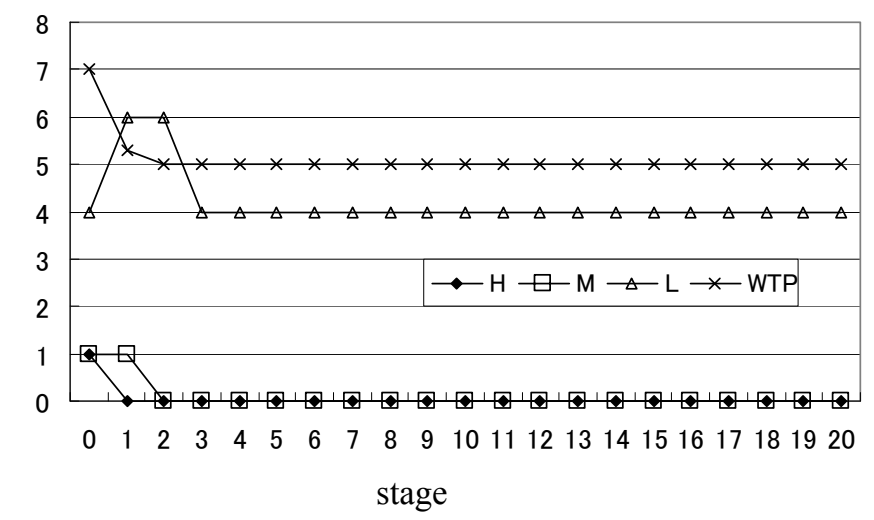

Figure 2. Example of a typical market for lemons

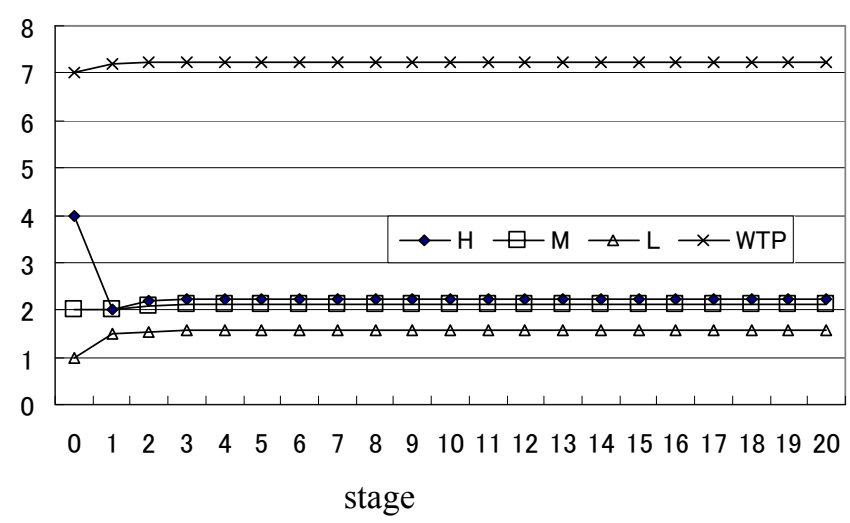

Figure 3. Example of an inconsistent case in a market for lemons

\subsection{Typical Market for Lemons}

Next, we modify the cost function as follows:

$$
M C\left(x_{i}\right)=k_{i} x_{i}+\alpha_{i}, i=H, M, L .
$$


Let us suppose $k_{H} \geq k_{M} \geq k_{L}$. We set $k_{H}=4, k_{M}=4, k_{L}=1, \alpha_{H}=4, \alpha_{M}=2, p_{H}=9, p_{M}=7$, and $p_{L}=5$. In this case, assumption 1 is satisfied. In the competitive markets, the sales for firms $\mathrm{H}, \mathrm{M}$, and $\mathrm{L}$ are 1 , 1 , and 4 , respectively. Therefore, we use these values as the initial sales values for each firm in the market for lemons.

In this case, products $\mathrm{H}$ and $\mathrm{M}$ diminish to zero at $t=1$ and 2 , respectively, while product $\mathrm{L}$ remains in the market (see Figure 2). This result is consistent with the assertion that higher-quality products exit a market for lemons.

\subsection{Inconsistent Case as the Market for Lemons}

Finally, we set $k_{H}=1, k_{M}=2, k_{L}=4, \alpha_{H}=4, \alpha_{M}=2, p_{H}=9, p_{M}=7$, and $p_{L}=5$. In the competitive markets, the sales for firms H, M, and L are 4, 2, and 1, respectively. Therefore, we use these values as the initial sales values for each firm in the market for lemons. This is an interesting case because the firms producing higher-quality products have more cost-effective production technologies (when ignoring $\alpha_{i}$ ).

The results are shown in Figure 3. They suggest that firms producing higher-quality products can increase their sales even in a market for lemons. It follows that, if the firms producing higher-quality products have cost-effective production technologies, they can increase their sales even in a market for lemons. Thus, the WTP in stage $t$ in the market for lemons may be higher than the initial WTP, as Figure 3 shows.

Proposition 2

If we remove assumption 1 , the following relationship may hold for $t>1$ :

$$
x_{H}^{t+1} \geq x_{H}^{t}, \quad x_{M}^{t} \geq x_{M}^{0} \text { and } x_{L}^{0}>x_{L}^{t}
$$

\section{Corollary 2}

If we remove assumption 1 , the WTP at some stage $t$ may be more than the initial WTP.

This result suggests that adverse selection does not occur among agricultural products even without a labelling system, possibly because the cost functions of the firms producing lower-quality products are in the upper ranges.

\section{Brief Discussion}

In sections 2 and 3, we revisited adverse selection in the context of food safety in our setting (assumption 1) and showed that the sales of firm $\mathrm{H}$ always decrease or are stable, while those of $\mathrm{L}$ increase or are stable and those of firm $M$ are not uniquely determined (Table 1). In section 4, we treated the special case of a usual market for lemons, where not only the sales of firm L but also those of firm M remain in the long run (subsection 4.1). Then, we demonstrated the typical case of a market for lemons, where only the sales of firm L remain in the market (subsection 4.2). Finally, we then removed assumption 1 and showed that the sales of H, M, and L all remain in the market in the long run (subsection 4.3).

As suggested in the Introduction, food safety levels rarely fall to the level of existing safety standards. Our results suggest that this occurs because not only the firm that produces the lowest-quality products but others can remain in the market. We further showed that even firms that produce the highest-quality products can increase their sales when we relax our assumption about cost function. It is often pointed out that a market for lemons will occur in food markets, but we do not necessarily observe this issue in real food markets, especially those in developed countries. Indeed, the present paper explained the gap between traditional explanations and real market behaviour.

Table 1. Comparison of the results

\begin{tabular}{ll}
\hline Conditions & Results \\
\hline Assumption 1 & $x_{H}^{0} \geq x_{H}^{t+1}$, and $x_{L}^{0} \leq x_{L}^{t+1}$ (Preposition 1) \\
$\quad$ & $x_{H}^{t}=0, x_{M}^{t}=x_{M}^{0}$, and $x_{L}^{t}=x_{L}^{0}$ for $t \geq 3$ (Figure 1) \\
Special case (sec. 4.1) & $x_{H}^{t}=0, x_{M}^{t+1}=0$, and $x_{L}^{t+2}=x_{L}^{0}$ for $t \geq 1$ (Figure 2) \\
Typical case (sec 4.2) & $x_{H}^{t+1} \geq x_{H}^{t}, x_{M}^{t} \geq x_{M}^{0}$, and $x_{L}^{t}>x_{L}^{0} \quad$ (Figure 3) \\
Removing assumption 1(sec. 4.3) &
\end{tabular}




\section{Conclusions}

This study's theoretical examinations and numerical simulations have explored why adverse selection in the food safety context does not seem to occur in the agricultural products market even when no labelling system is used. Food safety information is provided by public agencies and can be easily accessed and understood. Motivated by this information, consumers are willing to pay for products with average food safety levels. Although one expects adverse selection in the food safety context to occur in food markets, the food safety levels of agricultural products often remain higher than those mandated by public agencies' safety standards.

This study's theoretical examinations and numerical simulations indicate the following. First, let us suppose that the cost functions of firms producing higher-quality products are in the upper ranges. Our theoretical analysis showed that the magnitude of the relationship between $x_{M}^{0}$ and $x_{M}^{t}$ is not conclusive. Our numerical simulation indicates that firm M can remain in a market for lemons: the WTP at any stage $t$ is less than the initial WTP.

Second, we show that even firms producing the highest-quality products can remain in the lemon market and that firms producing middle-quality products can increase their sales if we relax our cost function assumption. Moreover, the WTP at some stage $t$ can be more than the initial WTP.

The literature posits that adverse selection occurs in a market for lemons. However, when we explicitly consider the difference in cost functions, not only can firms producing the lowest-quality product remain in the market, but others can as well, indicating that a market for lemons is not inevitable. These results, produced by theoretical analyses and numerical simulations, must be confirmed through research on real firms. This is a task for future research.

\section{References}

Albersmeier, F., Schulze, H., Jahn, G., \& Spiller, A. (2009). The reliability of third-party certification in the food chain: From checklists to risk-oriented auditing. Food Control, 20(10), 927-935. http://dx.doi.org/10.1016/j.foodcont.2009.01.010

Akerlof, G. A. (1970). The market for "lemons": Quality uncertainty and the market mechanism. Quarterly Journal of Economics, 84, 488-500. http://dx.doi.org/10.2307/1879431

Blaylock, J., Smallwood, D., Kassel, K., Variyam, J., \& Aldrich, L. (1999). Economics, food choices, and nutrition. Food Policy, 24(2-3), 269-286. http://dx.doi.org/10.1016/S0306-9192(99)00029-9

Cho, B. H., \& Hooker, N. H. (2007). Voluntary vs. mandatory approaches to food safety: Considering heterogeneous firms. Foodborne Pathogens and Disease, 4(4), 505-515. http://dx.doi.org/10.1089/fpd.2007.0007.

Crespi, J. M., \& Marette, S. (2001). How should food safety certification be financed? American Journal of Agrcultural Economics, 83(4), 852-861. http://dx.doi.org/10.1111/0002-9092.00214

Darby, M. R., \& Karni, E. (1973). Free competition and the optimal amount of fraud. Journal of Law and Economics, 16(1), 67-88. http://dx.doi.org/10.1086/466756

Drewnowski, D. (1997). Taste preferences and food intake. Annual Review of Nutrition, 17, 237-253. http://dx.doi.org/10.1146/annurev.nutr.17.1.237

Farina, E. M. M. Q., Gutman, G. E., Lavarello, P. J., Nunes, R., \& Reardon, T. (2005). Private and public milk standards in Argentina and Brazil. Food Policy, 30(3), 302-315. http://dx.doi.org/10.1016/j.foodpol.2005.05.008

Hammoudi, A., Hoffmann, R., \& Surry, Y. (2009). Food safety standards and agri-food supply chains: an introductory overview. European Review of Agricultural Economics, 36(4), 469-478. http://dx.doi.org/10.1093/erae/jbp044

Henson, S. J., \& Traill, W. B. (1993). The demand for food safety: market imperfections and the role of government. Food Policy, 18(2), 152-162. http://dx.doi.org/10.1016/0306-9192(93)90023-5

Jahn, G., Schramm, M., \& Spiller, A. (2005). The reliability of certification: Quality labels as a consumer policy tool. Journal of Consumer Policy, 28(1), 53-73. http://dx.doi.org/10.1007/s10603-004-7298-6

Latvala, T., \& Kola, J. (2002). Demand for and value of credence characteristics: Case beef, presented at the 10th Congress of the European Association of Agricultural Economists, Zaragoza, Spain, August 28-31, 2002. Retrieved from http://ageconsearch.umn.edu/bitstream/24841/1/cp02la04.pdf 
Nelson, P. (1970). Information and consumer behavior. Journal of Political Economy, 78(2), 311-329. http://dx.doi.org/10.1086/259630

Pritchett, L., \& Summers, L. H. (1996). Wealthier is healthier. Journal of Human Resources, 31(4), 841-868. http://dx.doi.org/10.2307/146149

Starbird, S. A. (2005). Moral hazard, inspection policy, and food safety. American Journal of Agricultural Economics, 87(1), 15-27. http://dx.doi.org/10.1111/j.0002-9092.2005.00698.x

Starbird, S. A., \& Amanor-Boadu, V. (2006). Do inspection and traceability provide incentives for food safety? Journal of Agricultural and Resource Economics, 31(1), 14-26.

Starbird, S. A., \& Amanor-Boadu, V. (2007). Contract selectivity, food safety, and traceability. Journal of Agricultural \& Food Industrial Organization, 5(1). http://dx.doi.org/10.2202/1542-0485.1141

Sykuta, M. (2005). Agricultural organization in an era of traceability. Journal of agricultural and applied economics, 37(2), 365-377.

Traill, W. B., \& Koenig, A. (2010). Economic assessment of food safety standard: Costs and benefits of alternative approaches. Food Control, 21, 1611-1619. http://dx.doi.org/10.1016/j.foodcont.2009.06.018

\section{Copyrights}

Copyright for this article is retained by the author(s), with first publication rights granted to the journal.

This is an open-access article distributed under the terms and conditions of the Creative Commons Attribution license (http://creativecommons.org/licenses/by/3.0/). 